\title{
Discriminating Patients Suffering from Non-Communica- ble Diseases : A Case Study Among Bangladeshi Adults
}

\author{
KC Bhuyan*1, Mortuza Ahmmed ${ }^{2}$ and Jannatul Fardus ${ }^{3}$ \\ ${ }^{1}$ Professor of Statistics, Jahangirnagar University, Bangladesh \\ ${ }^{2}$ Department of Mathematics, American International University, Bangladesh \\ ${ }^{3}$ Department of Mathematics, American International University, Bangladesh
}

Received: 制: September 29, 2018; Published: 制: October 16, 2018

*Corresponding author: KC Bhuyan, Professor of Statistics ( Retired) , Jahangirnagar University , Saver, Dhaka, Bangladesh

\begin{abstract}
Although half of annual mortality and almost half of the burden of disease in Bangladesh are for NCDs, less evidence are available to identify the variables responsible for NCDs. The aim of the present work is to identify the factors associated with NCDs in a representative sample of families of students of American International University - Bangladesh (AIUB). The most important variables responsible for the presence of non-communicable diseases among the Bangladeshi adults were age followed by marital status, body weight, level of education and other variables. These variables were identified by discriminant analysis. The study was based on 785 adult respondents from families of $2 \%$ randomly selected students. The students themselves collected the information through a pre-designed and pre-tested questionnaires. The collected information were residence, sex, age, height, weight, education, occupation, marital status, physical work, monthly income, family size, smoking habit and food habit along with suffering of any non-communicable disease and its treatment. Body Mass Index (BMI) was calculated from the collected data. The association of NCDs with social factors and BMI were observed using Chi-square test and hence identified the associated factors with NCDs.
\end{abstract}

The prevalence of NCDs was observed among $49.4 \%$ respondents and $85.3 \%$ of them were exclusively diabetic. Another $4 \%$ were suffering from diabetes and heart disease. Among the NCDs affected respondents $91.2 \%$ belonged to obese and overweight group of respondents. The odd ratio indicated that the prevalence of diabetes was 1.76 times higher among obese and overweight group of respondents compared to other groups.

Keywords: NCDs; Socioeconomic Variables; Discriminant Analysis

\section{Introduction}

Non-communicable disease (NCD) is a medical condition or disease that is non-infectious or non-transmissible. NCDs can refer to chronic diseases which last for long periods of time and progress slowly. Sometimes, NCDs result in rapid deaths such as autoimmune diseases, heart diseases, stroke, cancer, diabetes, chronic kidney disease, osteoporosis, Alzheimer's disease, cataracts and others. These diseases are the major health burden in the industrialized countries and are increasing rapidly in the developing countries owing to demographic transitions and changing lifestyles among the people. More than 36 million people die annually from NCDs $(63 \%$ of global deaths), including 14 million people who die too young before the age of 70 years [1,2]. More than $90 \%$ of these premature deaths from NCDs occur in low- and middle-income countries. Like many low-income countries around the world, Bangladesh is in the midst of an epidemiologic transition where the burden of disease is shifting from a disease profile dominated by infectious diseases, under-nutrition and conditions of child birth to one increasingly characterized by NCDs [3]. The NCDs are responsible for half of annual mortality $(51 \%)$ and almost half of the burden of disease (41\%) [4]. Recent estimate observed in 2006 indicate that NCDs represent $68 \%$ of total death as against only $11 \%$ of total deaths due to communicable diseases [3]. The major causes of death in Bangladesh gradually shifted from acute infectious and parasitic diseases to NCDs.

Diabetes is one of the major components of NCDs. It is associated with prolonged ill health and death due to vascular diseases [58]. Around 415 million people have diabetes in the world and 78 million people are in South-east Asia region; by 2040 this will rise to 140 million. Bangladesh is one of the 6 countries of South-east Asia. There were 7.1 million cases of diabetes in Bangladesh in 2015. The prevalence of diabetes in adults (20-79 years of age) was $7.4 \%$ in Bangladesh [9]. The risk factors for cardiovascular disease are glucose and lipid abnormalities and the prevalence of this disease is a major factor due to diabetes in both developed and developing countries [10]. Diabetes is prevalent among $10 \%$ people of Bangladesh and according to the International Diabetes 
Federation, the prevalence will be $13 \%$ by 2030 [10]. Tobacco smoking is another component of NCDs. It is widely used additive substance with an estimated 1.3 billion smokers worldwide and a global projected tobacco-induced death at over 6 million annually [12]. A household survey in Bangladesh estimated that tobacco-related illness was responsible for $16 \%$ of all deaths in the country [13]. It is observed from studies that some socioeconomic characteristics are responsible to enhance the diabetes and diseases related to tobacco smoking. In this paper our attempts is to identify socioeconomic characteristics responsible for NCDs.

\section{Methods}

The present analysis was conducted in the American International University - Bangladesh (AIUB) using the data collected from 785 respondents. The respondents are the family members of age 18 years and above of the randomly selected students of the university. Out of 10344 students during Fall 2015-16 semester, 2\% (207) were selected at random and were asked to collect information from their family members of age 18 years and above through a pre-designed questionnaire. Among the respondents, $388(49.4 \%)$ are suffering from at least one of the non-communicable diseases. The questionnaire contains questions related to socio-demographic characteristics of each person. It also contains questions related to type of disease, duration of suffering from the disease and information related to treatment. Some of the variables are qualitative in nature. For analytical purpose, all the variables were measured in nominal scores. In some studies, it was mentioned that Body Mass Index
$[B M I=$ Weight $($ in $\mathrm{kg}) /$ Height $($ in $\mathrm{cm} 2)]$ and obesity was associated with NCDs $[6,14]$. Accordingly, we tried to relate BMI with NCDs. The association of BMI with NCDs was studied by chi-square test. Association of BMI and diabetes were also studied here. Discriminant analysis was performed to discriminate the NCD affected and non NCD affected adults. The data was analyzed using SPSS version 20 .

\section{Results}

Among the 785 respondents 388 (49.4\%) were suffering from one or more of NCDs. The investigated units were classified by BMI and by other socioeconomic characteristics. The classification was also done by the presence of NCD and by other socioeconomic characteristics. The classified results were used to test the independence of any two characters. As shown in Table $186.6 \%$ respondents were from urban area and among them the prevalence rate of NCDs was $47.8 \%$ against the overall prevalence rate of NCDs $49.4 \%$. The differentials in prevalence of NCDs and residence

were significant $\left[\chi^{\wedge} 2=5.421, p-\right.$ value is 0.02$]$. The odd ratio[1.64] indicated that the urban people had 1.64 times more chance than the rural people to be affected by NCD. Among the respondents $68.8 \%$ were males and $47.2 \%$ of them were suffering from NCDs. The percentage of female respondents (54.3) who were suffering from NCDs was more. However, the differentials in proportions of male and female patients of NCDs were not statistically significant

$\left[\chi^{\wedge} 2=3.364, p-\right.$ value is 0.067$]$.

Table 1: Distribution of respondents by prevalence of NCDs and some socioeconomic factors.

\begin{tabular}{|c|c|c|c|c|c|c|}
\hline \multirow{3}{*}{ Residence } & \multicolumn{4}{|c|}{ Prevalence of NCDs } & \multirow{2}{*}{\multicolumn{2}{|c|}{ Total }} \\
\hline & \multicolumn{2}{|c|}{ Yes } & \multicolumn{2}{|c|}{ No } & & \\
\hline & $\mathbf{N}$ & $\%$ & $\mathbf{n}$ & $\%$ & $\mathbf{n}$ & $\%$ \\
\hline Rural & 63 & 60.0 & 42 & 40.0 & 105 & 13.4 \\
\hline Urban & 325 & 47.8 & 355 & 52.2 & 680 & 86.6 \\
\hline Total & 388 & 49.4 & 397 & 50.6 & 785 & 100.0 \\
\hline \multicolumn{7}{|l|}{ Sex } \\
\hline Male & 255 & 47.2 & 285 & 52.8 & 540 & 68.8 \\
\hline Female & 133 & 54.3 & 112 & 45.7 & 245 & 31.2 \\
\hline Total & 388 & 49.4 & 245 & 50.6 & 785 & 100.0 \\
\hline \multicolumn{7}{|l|}{ Marital Status } \\
\hline Married & 233 & 60.2 & 154 & 39.8 & 387 & 49.3 \\
\hline Unmarried & 146 & 38.0 & 238 & 62.0 & 384 & 48.9 \\
\hline Widow \& Divorced & 9 & 64.3 & 5 & 30.8 & 14 & 1.8 \\
\hline Total & 388 & 49.4 & 397 & 50.6 & 785 & 100.0 \\
\hline \multicolumn{7}{|l|}{ Religion } \\
\hline Muslim & 345 & 49.1 & 358 & 50.1 & 703 & 89.6 \\
\hline Hindu & 40 & 54.1 & 34 & 45.9 & 74 & 9.4 \\
\hline Others & 3 & 37.5 & 5 & 62.5 & 8 & 1.0 \\
\hline Total & 388 & 49.4 & 397 & 50.6 & 785 & 100.0 \\
\hline \multicolumn{7}{|l|}{ Age Groups (in Years) } \\
\hline$<20$ & 15 & 48.4 & 16 & 51.6 & 31 & 3.9 \\
\hline $20-25$ & 124 & 40.1 & 185 & 59.9 & 309 & 39.4 \\
\hline
\end{tabular}




\begin{tabular}{|c|c|c|c|c|c|c|}
\hline $25-30$ & 18 & 30.0 & 42 & 70.0 & 60 & 7.5 \\
\hline $30-45$ & 64 & 48.5 & 68 & 51.5 & 132 & 16.9 \\
\hline $45+$ & 167 & 66.0 & 86 & 34.0 & 253 & 32.3 \\
\hline Total & 388 & 49.4 & 397 & 50.6 & 785 & 100.0 \\
\hline \multicolumn{7}{|l|}{ Level of education } \\
\hline Illiterate & 15 & 68.2 & 7 & 31.8 & 22 & 2.8 \\
\hline Primary & 33 & 66.0 & 17 & 34.0 & 50 & 6.4 \\
\hline Secondary & 65 & 56.0 & 51 & 44.0 & 116 & 14.8 \\
\hline Graduate & 216 & 45.0 & 264 & 55.0 & 480 & 61.1 \\
\hline Post - graduate & 59 & 50.4 & 58 & 49.6 & 117 & 14.9 \\
\hline Total & 388 & 49.4 & 397 & 50.6 & 785 & 100.0 \\
\hline \multicolumn{7}{|l|}{ Occupation } \\
\hline Agriculture & 8 & 40.0 & 12 & 60.0 & 20 & 2.5 \\
\hline Business & 44 & 62.9 & 26 & 37.1 & 70 & 8.9 \\
\hline Service & 82 & 45.8 & 97 & 54.2 & 179 & 22.8 \\
\hline Retired & 25 & 61.0 & 16 & 39.0 & 41 & 5.2 \\
\hline Housewife & 76 & 75.2 & 25 & 24.8 & 101 & 12.9 \\
\hline Students & 142 & 40.2 & 211 & 59.8 & 353 & 45.0 \\
\hline Others & 11 & 52.4 & 10 & 47.6 & 21 & 2.7 \\
\hline Total & 388 & 49.9 & 397 & 50.6 & 785 & 100.0 \\
\hline \multicolumn{7}{|c|}{ Monthly Family Income (in Thousands) } \\
\hline$<10$ & 30 & 36.1 & 53 & 63.9 & 83 & 10.6 \\
\hline $10-20$ & 37 & 45.1 & 42 & 54.9 & 82 & 10.4 \\
\hline $20-30$ & 27 & 43.5 & 35 & 56.5 & 62 & 7.9 \\
\hline $30-40$ & 32 & 60.8 & 19 & 39.2 & 51 & 6.5 \\
\hline $40-50$ & 27 & 69.2 & 12 & 30.8 & 39 & 5.0 \\
\hline $60+$ & 36 & 55.4 & 29 & 44.6 & 65 & 8.3 \\
\hline No income & 200 & 49.6 & 203 & 50.4 & 403 & 51.3 \\
\hline Total & 388 & 49.4 & 397 & 50.6 & 785 & 100.0 \\
\hline \multicolumn{7}{|l|}{ Smoking Habit } \\
\hline Yes & 61 & 48.8 & 64 & 51.2 & 125 & 15.9 \\
\hline No & 320 & 49.4 & 328 & 50.6 & 648 & 82.5 \\
\hline Not Applicable & 7 & 58.3 & 5 & 41.7 & 12 & 1.5 \\
\hline Total & 388 & 49.4 & 397 & 50.6 & 785 & 100.0 \\
\hline \multicolumn{7}{|l|}{ Physical Labour } \\
\hline Yes & 194 & 47.2 & 217 & 52.8 & 411 & 52.4 \\
\hline No & 194 & 51.9 & 180 & 48.11 & 374 & 47.6 \\
\hline Total & 388 & 49.4 & 397 & 50.16 & 785 & 100.0 \\
\hline \multicolumn{7}{|c|}{ Habit of Taking Processed Food } \\
\hline Yes & 191 & 45.0 & 233 & 55.0 & 424 & 54.0 \\
\hline No & 197 & 54.6 & 164 & 45.4 & 361 & 46.0 \\
\hline Total & 388 & 49.4 & 397 & 50.6 & 785 & 100.0 \\
\hline \multicolumn{7}{|l|}{ Level of BMI } \\
\hline$<20$ & 6 & 23.1 & 20 & 76.9 & 26 & 3.3 \\
\hline $20-25$ & 28 & 34.6 & 53 & 65.4 & 81 & 10.3 \\
\hline $25-30$ & 191 & 48.0 & 207 & 52.0 & 398 & 50.7 \\
\hline $30+$ & 163 & 58.2 & 117 & 41.8 & 280 & 35.7 \\
\hline Total & 388 & 49.4 & 397 & 50.6 & 785 & 100.0 \\
\hline
\end{tabular}


The males were less exposed [odd ratio $=0.75$ ] to NCD compared to females. Among the respondents $49.3 \%$ were married. The prevalence rate of NCDs among them was $60.2 \%$. The prevalence was also higher among widow and divorced respondents. The differentials in prevalence rate by marital status of the respondents were significant $\left[\chi^{\wedge} 2=40.994, p\right.$-value was 0.000$]$. The chance of suffering of married person by NCD was more than two times than that of single person [ odd ratio $=2.37$ ]. As usual most respondents $(89.6 \%$ ) were Muslims but the prevalence rate (49.1\%) among them was not higher compared to the prevalence rate (54.1\%) among the Hindus. However, the differentials in prevalence rate by religion were not statistically significant $\left[\chi^{\wedge} 2=1.124, p\right.$-value is 0.57$]$. The muslims were less exposed to NCD than their non-muslim counterpart [ odd ratio $=0.87]$.

Most of the respondents (39.4\%) were in the age group 20 years and above but less than 25 years and among them prevalence rate of NCDs was $40.1 \%$. A big group (32.2\%) of respondents was of age 45 years and above and $66 \%$ of them were experienced of any of the
NCDs. The differentials in prevalence rate by age of the respondents were significant $\left[\chi^{\wedge} 2=47.631, p\right.$-value is 0.000$]$. Those who were of age group $45+$ years were more exposed to NCD than the persons of other ages [ odd ratio $=2.73$ ]. Among the respondents $61.1 \%$ were graduates and the prevalence rate of NCDs among them was $45 \%$. Among illiterate and primary educated people, the prevalence rates were higher and the differentials in prevalence rate according to level of education were significant $\chi^{\wedge} 2=14.426, p$-value is 0.006 . The illiterate people are 2.24 times more exposed to NCD than the literate people. Among the respondents $45 \%$ were students followed by service persons (22.8\%). The prevalence rate of NCDs among students was $40.2 \%$ and $45.8 \%$ among service persons. The worst affected group by NCDs was housewives followed by business persons and retired persons. In a separate study [15] the prevalence of diabetes was observed in higher rates among the similar three groups. In the present analysis, it was seen that diabetes was the main cause of NCDs (Table 2) and prevalence of diabetes was observed in higher rates among these three groups of respondents mentioned above.

Table 2: Distribution of respondents according to their residence and types of disease.

\begin{tabular}{|c|c|c|c|c|c|c|}
\hline \multirow{3}{*}{ Types of Disease } & \multicolumn{4}{|c|}{ Residence } & \multirow{2}{*}{\multicolumn{2}{|c|}{ Total }} \\
\hline & \multirow{2}{*}{$\begin{array}{c}\text { Rural } \\
\mathbf{N}\end{array}$} & \multirow[b]{2}{*}{$\%$} & \multicolumn{2}{|c|}{ Urban } & & \\
\hline & & & $\mathbf{n}$ & $\%$ & $\mathbf{n}$ & $\%$ \\
\hline Diabetes & 46 & 13.9 & 285 & 86.1 & 331 & 85.3 \\
\hline Heart disease & 10 & 29.4 & 24 & 70.6 & 34 & 8.8 \\
\hline Diabetes and Heart disease & 5 & 35.7 & 9 & 64.3 & 14 & 3.6 \\
\hline Hypertension & 1 & 16.7 & 5 & 83.3 & 6 & 1.5 \\
\hline Others & 1 & 33.3 & 2 & 67.7 & 3 & 0.5 \\
\hline Total & 63 & 16.2 & 325 & 83.8 & 388 & 100.0 \\
\hline
\end{tabular}

The differentials in prevalence rate by occupation of the respondents were significant $\left[\chi^{\wedge} 2=47.852, p-\right.$ value is 0.000$]$. The farmers were less exposed to NCD than the people of any other profession [ odd ratio $=0.675$ ]. Only $5 \%$ respondents had income above take 40 to 50 thousands and higher proportion of this group of respondents was affected by NCDs. The next higher affected group was observed among the respondents having income Taka 30 to 40 thousands (60.8\%). The proportions of affected groups of respondents having different levels of income were significantly different $\left[\chi^{\wedge} 2=17.003, p\right.$-value is 0.009$]$. The heart diseases are associated with smoking habit $[5,15]$ and heart diseases are components of NCDs. In our study it was observed that among the smokers the prevalence rate of NCDs was $48.8 \%$. This proportion was higher (58.3\%) among the respondents for whom there was no question of smoking. However, the proportions of prevalence of NCDs among smokers and non-smokers were not significantly different. Smokers and nonsmokers were almost similarly exposed to NCD [ odd ratio $=0.97]$.

In many studies it is reported that diabetes is significantly related to non-involvement of physical labour [6,7] and the disease is an important cause of NCDs. In the present analysis, it was seen that $52.4 \%$ respondents were involved in physical la- bour and prevalence rate of NCDs among this group of people was $47.2 \%$. The corresponding figure for other group of people was $51.9 \%$. This proportion of prevalence of NCDs among the respondents who did not do any physical labour was slightly higher. But the differentials in proportions were not statistically significant

$\left[\chi^{\wedge} 2=1.708, p-\right.$ value is 0.191$]$ [ odd ratio $=0.83$ ]. Most of the respondents $(54 \%)$ were habituated in taking canned or processed food from the market. The prevalence rate among them was $45 \%$. The corresponding figure among the respondents who were not habituated with canned or processed food was $54.6 \%$. This difference in proportions was significant $\left[\chi^{\wedge} 2=7.075, p\right.$-value is 0.008$]$. The result did not indicate that processed food was responsible for NCDs as the prevalence of it was less among the respondents who were habituated with processed food. Obesity (BMI $\geq 30$, [14]) is generally associated to a significantly higher risk of arterial hypertension, diabetes, hepatic steatosis and other diseases of NCDs.

In our present analysis we observe that the level of BMI is significantly associated with the prevalence of NCDs $\left[\chi^{\wedge} 2=23.355, p\right.$-value is 0.000$]$. Among the NCDs patients $85.3 \%$ (Table 2) were suffering from diabetes. This percentage was higher as most of the respondents were from urban area. It indicated that urban people were more diabetic. This finding is similar with the 
finding observed at national level [15] and in other sample study [16], where more urban people were diabetic patients $[15,16]$. This study also indicated that diabetic was one of the biggest causes of NCDs [1]. The differentials in types of disease by residence was significant $\left[\chi^{\wedge} 2=10.222, p\right.$-value $\left.=0.037\right]$. It is seen that higher rates of prevalence were observed among over weight (BMI 25 to less than 30) and obese group of people [15]. The prevalence of NCDs among these two groups was $52.2 \%$. The prevalence rate was 2.52 times more among these two groups ( $\mathrm{OR}=2.52)$ compared to other two groups. Confidence interval for OR is 1.52 to 3.63 . The present analysis also indicated that diabetes was the main factor of NCDs (85.3\% are exclusively diabetic). Among the diabetic patients overweight and obese group of respondents was higher in proportion (90.3\%) (Table 3).

Table 3: Distribution of respondents according to level of BMI and prevalence of diabetes.

\begin{tabular}{|c|c|c|c|c|c|c|}
\hline \multirow{3}{*}{ Level of BMI } & \multicolumn{4}{|c|}{ Prevalence of Diabetes } & & \\
\hline & \multicolumn{2}{|c|}{ Yes } & \multicolumn{2}{|c|}{ No } & \multicolumn{2}{|c|}{ Total } \\
\hline & $\mathbf{N}$ & $\%$ & $\mathbf{n}$ & $\%$ & $\mathbf{n}$ & $\%$ \\
\hline$<20$ & 6 & 23.1 & 20 & 76.9 & 26 & 3.3 \\
\hline $20-25$ & 27 & 33.3 & 54 & 66.7 & 81 & 10.3 \\
\hline $25-30$ & 166 & 41.7 & 232 & 58.3 & 398 & 50.7 \\
\hline $30+$ & 132 & 47.1 & 148 & 52.9 & 280 & 35.7 \\
\hline Total & 331 & 43.7 & 454 & 56.3 & 785 & 100.0 \\
\hline
\end{tabular}

The differences in proportions according to level of BMI and prevalence of diabetes were significantly different $\left[\chi^{\wedge} 2=9.355, p\right.$-value is 0.025$]$. The prevalence of diabetes among the obese and overweight group of people was 1.76 times higher compared to other groups [16]. Confidence interval for OR is 1.14 to 2.72. Around $32 \%$ respondents were of age greater than or equal to 45 years and $50.6 \%$ of them were exclusively diabetic (Tables $4 \& 5$ ). This proportion of diabetic patients was lower among the respondents of other age groups. The odds ratio (1.65) indicated that the prevalence of diabetes among the respondents of age greater than or equal to 45 years was 1.65 times than that of other age groups. The $95 \%$ confidence interval for odds ratio is 1.30 to 2.10 . The lowest prevalence of diabetes (30\%) was observed among the agriculturists. The highest prevalence rate (47.1\%) was observed among the business persons. The differences in proportions of prevalence of diabetes according to different levels of profession were statistically significant $\left[\chi^{\wedge} 2=15.204, p\right.$-value is 0.019$]$. The result of odds ratio (1.25) indicated that the prevalence of diabetes was 1.25 times more among business persons compared to persons of other professions. The $95 \%$ confidence interval for odds ratio is 0.76 to 2.04 . The most important variables to discriminate status, weight, education, etc. The importance between NCD affected people and non- of variables were studied by the magnitude of affected people were age followed by marital the correlation coefficient of the variables and the discriminant function score [19].

Table 4: Distribution of respondents by prevalence of diabetes and demographic factors.

\begin{tabular}{|c|c|c|c|c|c|c|}
\hline \multirow{3}{*}{$\begin{array}{l}\text { Age Groups (in } \\
\text { Years) }\end{array}$} & \multicolumn{4}{|c|}{ Prevalence of Diabetes } & \multirow{2}{*}{\multicolumn{2}{|c|}{ Total }} \\
\hline & \multicolumn{2}{|c|}{ Yes } & \multicolumn{2}{|c|}{ No } & & \\
\hline & $\mathbf{n}$ & $\%$ & $\mathbf{n}$ & $\%$ & $\mathbf{n}$ & $\%$ \\
\hline$<20$ & 15 & 48.4 & 16 & 51.6 & 31 & 3.9 \\
\hline $20-25$ & 123 & 39.8 & 186 & 60.2 & 309 & 39.4 \\
\hline $25-30$ & 45 & 25.0 & 45 & 75.0 & 60 & 7.6 \\
\hline $30-45$ & 50 & 37.9 & 82 & 62.1 & 132 & 16.8 \\
\hline $45+$ & 128 & 50.6 & 125 & 49.4 & 253 & 32.2 \\
\hline Total & 331 & 42.2 & 454 & 57.8 & 785 & 100.0 \\
\hline \multicolumn{7}{|l|}{ Profession } \\
\hline Agriculture & 6 & 30.0 & 14 & 70.0 & 20 & 2.5 \\
\hline Business & 33 & 47.1 & 37 & 52.9 & 70 & 8.9 \\
\hline Service & 69 & 38.5 & 110 & 61.5 & 179 & 22.8 \\
\hline Retired & 15 & 36.6 & 26 & 63.4 & 41 & 5.2 \\
\hline Housewife & 42 & 41.6 & 59 & 58.4 & 101 & 12.9 \\
\hline Student & 141 & 39.9 & 212 & 60.1 & 353 & 45.0 \\
\hline Others & 8 & 38.1 & 13 & 61.9 & 21 & 2.7 \\
\hline Total & 331 & 42.2 & 454 & 57.8 & 785 & 100.0 \\
\hline
\end{tabular}


Table 5: Standardized discriminant coefficient and the correlation coefficient of variable and discriminant function score.

\begin{tabular}{|c|c|c|c|c|c|}
\hline Variable, $x_{i}$ & Discriminant Coefficient & $\begin{array}{l}\text { Correlation Coefficient of Variable and } \\
\text { Discriminant Function Score }\end{array}$ & Wilk's $\Lambda$ & $\begin{array}{c}\chi^{2} \\
\text { Value }\end{array}$ & p-Value \\
\hline Age & 0.480 & 0.701 & & & \\
\hline Marital status & -0.340 & -0.570 & & & \\
\hline Weight & 0.392 & 0.307 & & & \\
\hline Education & -0.279 & -0.307 & & & \\
\hline Process food & 0.148 & 0.281 & & & \\
\hline Height & -0.230 & -0.270 & & & \\
\hline Residence & -0.221 & -0.246 & & & \\
\hline Income & 0.475 & 0.205 & & & \\
\hline Gender & 0.010 & 0.194 & & & \\
\hline Restaurant food & -0.010 & 0.191 & & & \\
\hline Physical work & 0.147 & 0.138 & & & \\
\hline Food habit & 0.008 & 0.047 & & & \\
\hline Smoking & -0.027 & 0.036 & & & \\
\hline
\end{tabular}

\section{Discussion}

The study was based on data collected from 785 adult respondents of 207 families. The families were the families of randomly selected students of American International University - Bangladesh (AIUB). Among the respondents 388 were suffering from at least one of the non-communicable diseases. Among this group $85.3 \%$ were exclusively suffering from diabetes. Similar higher rate of diabetic group among NCDs affected people were also observed in other studies [5-8]. Among the diabetic patients $91.2 \%$ respondents were of obese and overweight group. Similar to other studies, tobacco smoking is another source of NCDs [12]. In the present analysis $15.9 \%$ were smokers. This percentage among the respondents who were exposed to NCDs is 15.7. The study indicated that tobacco smoking was not significantly associated with NCDs. The NCDs were significantly associated with residence, marital status, age, education, occupation, income, physical labour and BMI. Discriminant analysis also supported this fact. The association was studied by $\chi^{\wedge} 2$ test. The prevalence rate of NCDs among urban people was $47.8 \%$. But this rate was higher (60\%) among the rural people. The prevalence of NCDs was observed higher (60.2\%) among the married respondents.

Among the respondents $32.2 \%$ were of the age group 45 years and above and $66 \%$ of them were exposed to NCDs. Major NCDs exposed respondents were diabetic and among the diabetic patients $38.7 \%$ were of age group 45 years and above. This finding is similar to that observed in home and abroad $[15,16,18]$. The prevalence of NCDs among illiterate people was the highest (68.2\%) followed by primary and secondary level educated respondents. Among housewives the prevalence of NCDs was the highest (75.2\%) followed by business persons and retired persons. Among the respondents $19.7 \%$ were of income group 30 thousand or more per month and among them the prevalence of NCDs was $56.8 \%$. The prevalence of NCDs was significantly different among respondents of different income levels. The prevalence of NCDs was low among the respondents (47.2\%) who were involved in any type of physical work. Among the respondents obesity and overweight (BMI $\geq 25+$ ) were more prevalent (86.4\%). The prevalence of NCDs was significantly more among these two groups of respondents. This obesity is one of the risk factor of prevalence of NCDs and it enhances arterial hypertension, diabetes, renal failure etc [14]. In this study also it was observed that higher prevalence rate (90\%) of diabetes was observed among respondents of obesity and overweight. The discriminant analysis showed that the variables age, followed by marital status and weight were the most important variables in discriminating the two groups of adults. Similar findings were observed in both home and abroad $[1,3,4,15,16]$. NCDs are the major health burden in both developed and developing countries. The incidence of NCDs cannot be avoided, but its prevalence can be reduced by implementing appropriate action plan. The following actions are very important to reduce the prevalence rate. These are

a) Halt the rise in diabetes by encouraging people to participate in blood screening programs and to encourage them to do some sorts of physical labour.

b) Motivation campaign is to be conducted to reduce tobacco consumption by informing the people about the health hazard of tobacco consumption.

c) To motivate eligible people to join counseling campaign for drug therapy so that heart attacks can be reduced.

d) To take action for availability of affordable basic technologies and essential medicines to treat major noncommunicable diseases.

e) To motivate people so that they become careful about the danger of obesity and its adverse effect of health. The public health authority can play a decisive role for the above steps.

\section{References}

1. WHO (2013) Global action plan for the prevention and control of NCDs 2013-2020: 1-2. 
2. Omran AR (1971) The epidemiological transition: a theory of the epidemiology of population change. Milbank Memorial Fund Quaterly 49(4): 509-538.

3. Karar ZA, Alam N, Streatfield PK (2009) Epidemiological transition in rural Bangladesh. Global Health Action 19: 2.

4. (2007) Bangladesh Bureau of Statistics. Statistical Pocket Book of Bangladesh.

5. WHO (2004) Death and Daily estimates for 2002 by Cause for WHO member states.

6. Lozano R, Naghvi M, Foreman K, Lim S, Shibuya K, et al. (2012) Global and regional mortality from 235 causes of death for 20 age groups in 1990 and 2010: a systematic analysis for the global burden of disease study 2010. Lancet 380 (9859): 2095-2128.

7. Murray CJL, Vos T, Lozazo R, Naghavi M, Flaxman AD, et al. (2012) Disability adjusted life years for 291 disease and injuries in 21 regions, 1990-2010, a systematic analysis for the global burden of disease study 2010. Lancet 2012 380(9589): 2197-2223.

8. (2016) Bhuyan KC, Fardus J, Rahman S. Relationship between socioeconomic factors and diabetes among urban and rural people of Bangladesh. Global Journal of Quantitative Science.

9. Silink M, Tuomilehto J (2011) Prevention and control of diabetes with a focus on low and middle income countries, paper 6, A prioritized research agenda for prevention and control of non-communicable diseases.

10. Prakashchandra RD, Naido DP (2016) Glycaemic control profile in diabetic patients: A sub-analysis of the phoenix lifestyle project. Euromediterranean Biomedical Journal 11(05): 33-39.

\section{ISSN: 2574-1241}

DOI: 10.26717/BJSTR.2018.10.001898

KC Bhuyan. Biomed J Sci \& Tech Res

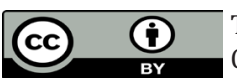

This work is licensed under Creative Commons Attribution 4.0 License

Submission Link: https://biomedres.us/submit-manuscript.php
11. International Diabetes Federation (IDF) (2011) Diabetes atlas, ( $6^{\text {th }}$ Edn.). (internet). Country estimates table 2011, The International Diabetes Federation.

12. Bhuyan KC, Fardus J, Khanam M (2016) Discriminating the students of universities by their smoking habit. AJSE 15(1).

13. WHO (2007) Impact of tobacco-related illness in Bangladesh. New Delhi, World Health Organization.

14. Calamusa G, Amodio E, Costantino C, Maria Di Pasquale, Viviana Gelsomino, et al. (2012) Body mass index and factors associated with overweight and obesity; A cross-sectional study of adult subjects living in a small city of Western Sicily (Italy). Italian Journal of Public Health Volume 9(3): 7539.

15. Fardus J, Bhuyan KC (2016) Discriminating diabetic patients of some rural and urban areas of Bangladesh, A discriminant analysis approach. Euromediterranean Biomedical Journal 11(19): 33-39.

16. Akter S, Rahaman MM, Sarah Krull Abe, Sultana S (2014) Prevalence of diabetes and their risk factors among Bangladeshi adults: a nationwide survey. Bull World Health Organ 92(3): 204-213.

17. Altman DG. Practical Statistics for Medical Research, London, Chapman and Hall.

18. Sudeep S (2012) Silent killer, economic opportunity: Rethinking noncommunicable disease, Centre on Global Health Security World Bank.

19. Bhuyan KC (2005) Multivariate Analysis and its Applications, New Central Book Agency (P) Ltd, India.

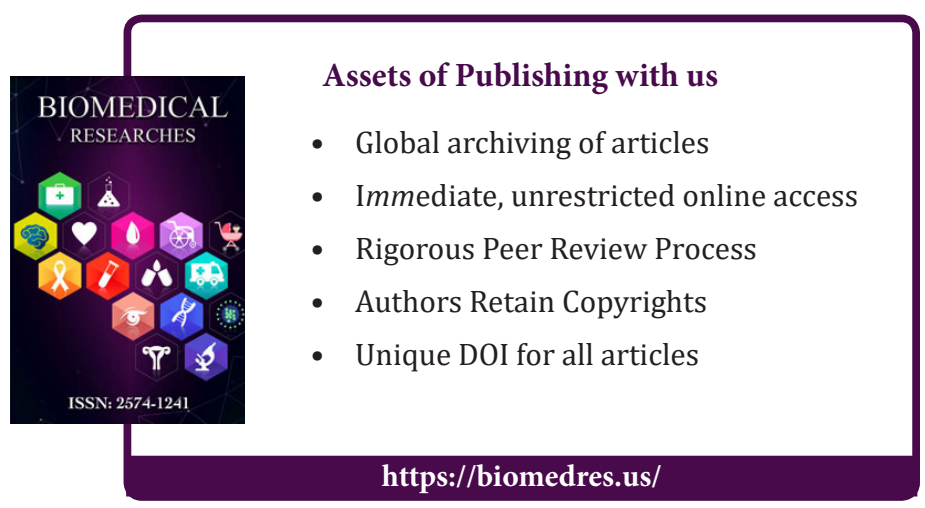

